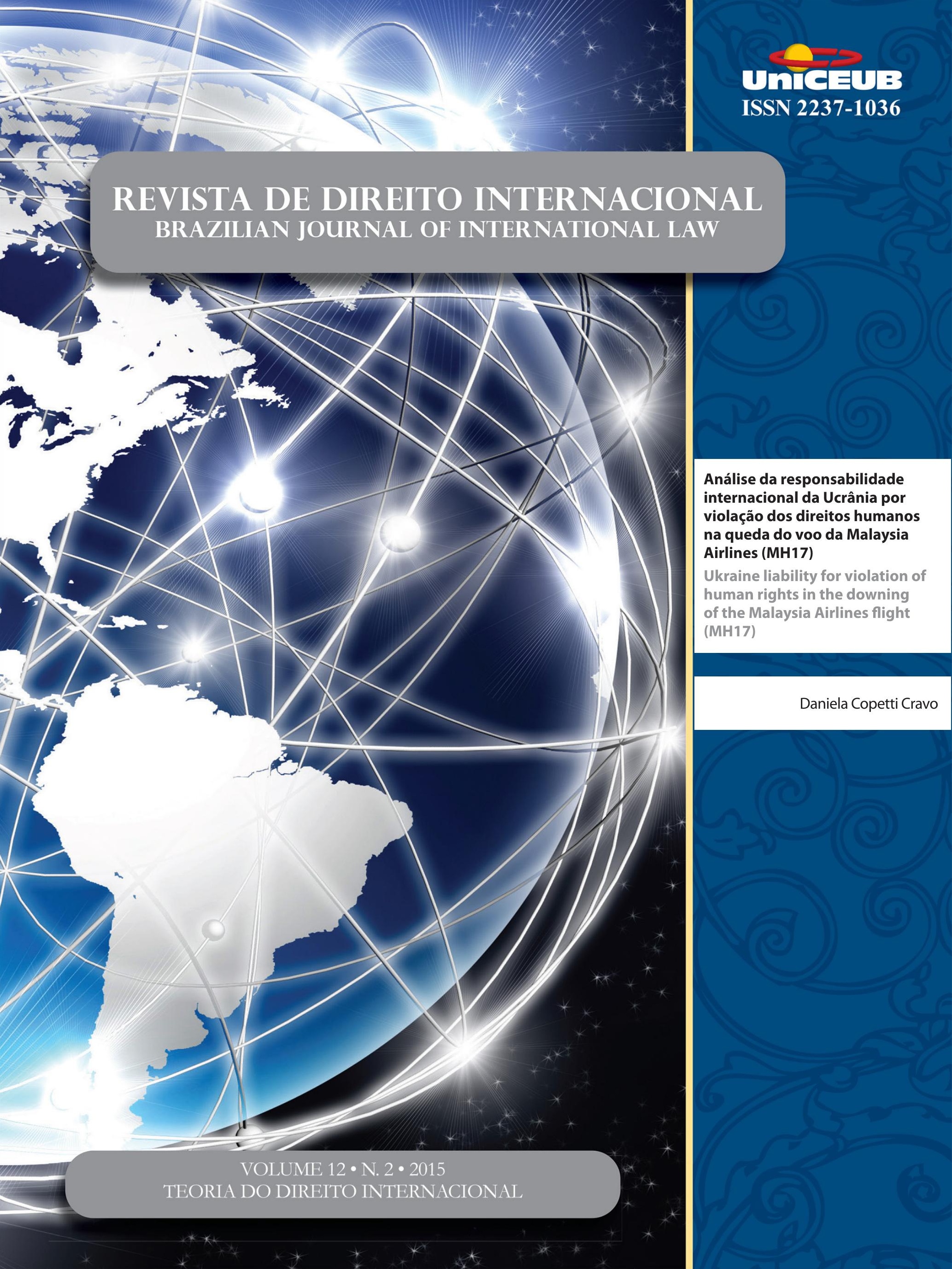




\section{Sumário}

CrôNiCAS DA ATUALIDADE do DiREITo INTERnACIONAL ..................................................... 2 Sarah Dayanna Lacerda Martins Lima, Carina Costa de Oliveira e Erika Braga

CrôniCas do Direito InternaCional dos InVESTIMENTOS ..............................................12 Nitish Monebhurrun

Por que voltar a Kelsen, o jurista do século XX ? 16 Inocêncio Mártires Coelho

O Princípio da Efetividade como conteúdo da norma fundamental (GrundNorm) DE KELSEN

Carlos Alberto Simões de Tomaz e Renata Mantovani de Lima

A JURIDIFICAÇÃo DE CONFLITOS POLÍTICOS NO DIREITO INTERNACIONAL PÚBLICO CONTEMPORÂ-

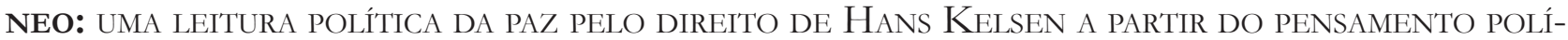
TICO De Claude Lefort

Arthur Roberto Capella Giannattasio

O SINCRETISMO TEÓRICO NA APROPRIAÇÃO DAS TEORIAS MONISTA E DUALISTA E SUA QUESTIONÁVEL UTILIDADE COMO CRITÉRIO PARA A CLASSIFICAÇÃO DO MODELO BRASILEIRO DE INCORPORA-

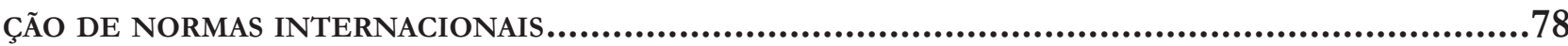
Breno Baía Magalhães

Direito Global em Pedaços: Fragmentação, Regimes e Pluralismo .98 Salem Hikmat Nasser

Por uma TeOria JURÍdica da INTEGRaÇão REgIONAL: A INTER-RELAÇÃO DiREITO INTERNO, DiREITO INTERNACIONAL PÚBLICO E DIREITO DA INTEGRAÇÃO Jamile Bergamaschine Mata Diz e Augusto Jaeger Júnior

A teOria DA INTERCONSTITUCIONALIDADE: UMA ANÁlISE COM BASE NA AMÉRICA LATINA...........160 Daniela Menengoti Ribeiro e Malu Romancini 
O DIÁLOGO HERMENÊUTICO E A PERGUNTA ADEQUADA À APLICAÇÃo DOS TRATADOS INTERNACIONAIS DE DIREITOS HUMANOS NO BRASIL: CAMINHOS PARA O PROCESSO DE INTERNACIONALIZAÇÃO

DA CONSTITUIÇÃO...................................................................................... 176

Rafael Fonseca Ferreira e Celine Barreto Anadon

O DIREITO COMPARADO NO STF: INTERNACIONALIZAÇÃO DA JURISDIÇÃO CONSTITUCIONAL BRASILEIRA

Carlos Bastide Horbach

THE PHILOSOPHY OF INTERNATIONAL LAW IN CONTEMPORARY SCHOLARSHIP: OVERCOMING NE-

GLIGENCE THROUGH THE GLOBAL EXPANSION OF HUMAN RIGHTS

Fabrício Bertini Pasquot Polido, Lucas Costa dos Anjos e Vinícius Machado Calixto

OpORTUNIDADES E DESAFIOS DAS TWAIL NO CONTEXTO LATINO-AMERICANO A PARTIR DE PERSPECTIVAS DOS POVOS INDÍGENAS AO DIREITO INTERNACIONAL

Fernanda Cristina de Oliveira Franco

Por Que uma ANÁlise ECONÔMICA Do DIREITO INTERNACIONAL PÚBLICO? DESAFIOS E PERSPECTIVAS DO MÉTODO NO BRASII

Gustavo Ferreira Ribeiro e Jose Guilherme Moreno Caiado

ANÁliSE ECONÔMICA do DIREITO INTERNACIONAL .263 Michele Alessandra Hastreiter e Luís Alexandre Carta Winter

RACIONALIDADE ECONÔMICA E OS ACORDOS BILATERAIS DE INVESTIMENTO 284 Michele Alessandra Hastreiter e Luís Alexandre Carta Winter

LOOKING FOR A BRICS PERSPECTIVE ON INTERNATIONAL LAW .304 Gabriel Webber Ziero

A INFLUÊNCIA DO DIREITO DESPORTIVO TRANSNACIONAL NO ORDENAMENTO JURÍDICO BRASILEIRO: DA REPRODUÇÃO DE NORMAS À APLICAÇÃO DIRETA PELA JURISDIÇÃO ESTATAL.......................3324 Tiago Silveira de Faria

CONVENCIONALIZAÇÃo DO DIREITO CIVIL: A APLICAÇÃo DOS TRATADOS E CONVENÇÕES INTERNACIONAIS NO ÂMBITO DAS RELAÇÕES PRIVADAS . 
NATIONAL JUdGES AND COURTS AS INSTITUTIONS FOR GLOBAL ECONOMIC GOVERNANCE 356

Juízes e tribunais nacionais como instituições para a governança global 356 Camilla Capucio

Is Trade Governance Changing? 371 Alberto do Amaral Júnior

OS FUNDOS ABUTRES: MEROS PARTICIPANTES DO CENÁRIO INTERNACIONAL OU SUJEITOS PERANTE O DIREITO INTERNACIONAL? 384

Guilherme Berger Schmitt

SHAREHOLDER AGREEMENTS IN PUBLICLY TRADED COMPANIES: A COMPARISON BETWEEN THE

U.S. AND BRAZIL. 402 Helena Masullo

REgulaÇÃo DO INVESTIMENTO ESTRANGEIRO DIRETO NO BRASIL: DA RESISTÊNCIA AOS TRATADOS BILATERAIS DE INVESTIMENTO À EMERGÊNCIA DE UM NOVO MODELO REGULATÓRIO 421 Fabio Morosini e Ely Caetano Xavier Júnior

DA QUALIFICAÇÃo JURÍDiCA dAS Distintas FORMAS DE PRESTAÇão TECNOLÓGICA: BREVE ANÁLISE DO MARCO REGULATÓRIO INTERNACIONAL

Daniel Amin Ferraz

REDEFINING TERRORISM: THE DANGER OF MISUNDERSTANDING THE MODERN WORLD'S GRAVEST THREAT

Jennifer Breedon

As EXECUÇões SELETIVAS E A RESPONSABILIZAÇÃo DE AGENTES TERRORISTAS 485 Alexandre Guerreiro

INTERNATIONAL CRIMINALS AND THEIR VIRTUAL CURRENCIES: THE NEED FOR AN INTERNATIONAL EFFORT IN REGULATING VIRTUAL CURRENCIES AND COMBATING CYBER CRIME Joy Marie Virga

Criminalidad transnacional organizada en el Ámbito del MERCOSUR: ¿Hacia un Derecho Penal Regional?. .528 Nicolás Santiago Cordini e Mariano Javier Hoet 
RUMO À INTERNACIONALIZAÇÃo DA PROTEÇÃO PENAL DO MEIO AMBIENTE: DOS ECOCRIMES AO ECOCÍDIO

Kathia Martin-Chenut, Laurent Neyret e Camila Perruso

Engaging the U.N. Guiding Principles on Business and Human Rights: the inter-AMERICAN COMMISSION ON HUMAN RIGHTS \& THE EXTRACTIVE SECTOR 571 Cindy S. Woods

O DIREITO HUMANO À COMUNICAÇÃo PRÉVIA E PORMENORIZADA DAS ACUSAÇÕES NOS PROCESSOS administrativos: O desprezo do Superior Tribunal de Justiça ao Pacto de San José da Costa Rica e À Corte Interamericana de Direitos Humanos .590

Daniel Wunder Hachem e Eloi Pethechust

A responsabilidade internacional do Brasil em FaCe do CONTRole de ConVENCionaliDADE EM SEDE DE DIREITOS HUMANOS: CONFLITO DE INTERPRETAÇÃO ENTRE A JURISDIÇÃO DA Corte Interamericana de Direitos Humanos e o Supremo Tribunal Federal quanto a LEI DE ANISTIA 612

Carla Ribeiro Volpini Silva e Bruno Wanderley Junior

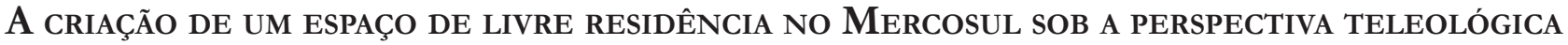
DA INTEGRAÇÃo REGIONAL: ASPECTOS NORMATIVOS E SOCIAIS DOS ACORDOS DE RESIDÊNCIA ....... 631

Aline Beltrame de Moura

A funcionalização como tendênCia evolutiva do Direito Internacional e sua conTRIBUIÇÃO AO REGIME LEGAL DO BANCO DE DADOS DE IDENTIFICAÇÃO DE PERFIL GENÉTICO NO BRASIL

Antonio Henrique Graciano Suxberger

O DIREITO INTERNACIONAL E A PROTEÇÃO DOS DIREITOS DE CRIANÇAS E DE ADOLESCENTES EM CONFLITO COM A LEI EM MOÇAMBIQUE

Bernardo Fernando Sicoche

ObTenÇão de PRovas no EXTERIOR: PARA ALÉM dA LEX FORI E LEX DiLigENTIAE. .685 André De Carvalho Ramos 
A Slight Revenge and a Growing Hope for Mauritius and the Chagossians: The UNClos Arbitral Tribunal's Award of 18 March 2015 on Chagos Marine Protected Area (Mauritius v. United Kingdom)

Géraldine Giraudeau

ANÁLISE DA RESPONSABILIDADE INTERNACIONAL DA UCRÂNIA POR VIOLAÇÃo DOS DIREITOS HUmanos na QUeda do voo da Malaysia Airlines (MH17). .728

Daniela Copetti Cravo

NatureZa JURÍdica do DESENVOLVIMENTO SUSTENTÁVEL No DIREITO INTERNACIONAL ........739 Pedro Ivo Diniz

A INFLUÊNCIA Da SOFT LAW NA FORMaÇão do DiREITo AMBIENTAL .767 Leonardo da Rocha de Souza e Margareth Anne Leister

As COMPLICADAS INTER-RELAÇÕES ENTRE OS SISTEMAS INTERNOS E INTERNACIONAIS DE PROTEÇãO DO DIREITO AO MEIO AMBIENTE SADIO. 785 José Adércio Leite Sampaio e Beatriz Souza Costa 


\title{
Análise da responsabilidade internacional da Ucrânia por violação dos direitos humanos na queda do voo da Malaysia Airlines (MH17)*
}

\author{
Ukraine liability for violation of human \\ rights in the downing of the Malaysia Airlines \\ flight (MH17)
}

Daniela Copetti Cravo**

\section{Resumo}

Sequer as investigações oficiais do abate do Voo MH17 no espaço aéreo da Ucrânia foram finalizadas, mas o caso já chegou à Corte Europeia de Direitos Humanos, por meio de ação movida por familiares de vítimas. Esses buscam a responsabilização da Ucrânia por violação dos direitos humanos; mas será que esta pode ser responsabilizada? Houve omissão pelo não fechamento do espaço aéreo? E, em caso positivo, qual é o fórum mais oportuno para buscar tal responsabilização? Não se deve falar em responsabilidade extraterritorial da Rússia? O propósito desse estudo, que se apoia no método dedutivo de abordagem de dados, consiste em tecer algumas possíveis respostas a tais questões, as quais apontam, como conclusão, para a responsabilidade da Ucrânia pela sua omissão ao não prudentemente fechar o seu espaço aéreo.

Palavras-chave: Voo MH17. Responsabilidade internacional. Corte Europeia de Direitos Humanos.

\section{Abstract}

Notwithstanding that not even the official investigations concerning the attack on the MH17 Flight around the Ukrainian airspace were concluded, the case has already arrived at the ECHR (European Court of Human Rights), through a lawsuit filed by the victim's families. Such lawsuit seeks to promote the responsibility of Ukraine for violating human rights. The issues that arise in this context are: is it possible to hold Ukraine accountable for this situation? Was there an omission by Ukraine's authorities for not shutting down it's airspace? Regarding this possibility, is the ECHR the most convenient forum to seek such responsibility? Could the extraterritorial responsibility of the Russian Federation be considered? Thus, the main purpose of this study, which relies on a deductive approach, is to bring forth some possible answers to this issue. Our efforts, therefore, point out to the plausibility of the accountability of Ukraine for failing to not act prudently and for not closing it's airspace during this conjuncture.

** Mestre e Doutoranda em Direito pela UFRGS. E-mail: danielacopetticravo@hotmail. com.
Recebido em 02/08/2015

Aprovado em 09/09/2015 
Keywords: MH17 flight. International responsibility. European Court of Human Rights.

\section{INTRODUÇão}

A Ucrânia, logo após decidir não assinar acordo com a União Europeia em 2013, passou a vivenciar sua maior crise desde a independência. O movimento que começou com protestos em Kiev, rapidamente se espalhou pelo país inteiro, tendo como pauta principal a mudança de regime e o protesto contra a corrupção.

Nessa senda, o governo se desestabilizou e os conflitos sociais evoluíram. Abriu-se, pois, uma janela de oportunidade para a região da Crimeia ${ }^{1}$ tão próxima cultura e etnicamente da Rússia ${ }^{2-3}$, sair do controle jurisdicional da Ucrânia.

Assim, no desenrolar de toda instabilidade institucional e social, houve a anexação formal pela Rússia da Crimeia. Essa, muito embora tenha sido referendada pela população local ${ }^{4-5}$, foi considerada ilegal no âmbito da ONU, por meio de adoção de Resolução pela Assembleia Geral (A/RES/68/262).

A anexação foi - justamente - o gatilho das lutas entre os movimentos pró-Rússia, que ganharam corpo em várias outras regiões da Ucrânia além da Crimeia e as forças ucranianas, mobilizadas por decreto do Presidente Ucraniano para conter as ameaças e agressões à integridade territorial do país.

1 MARXSEN, Christin. The crimea crisis: an international law perspective. Zeitschrift ausländisches öffentliches Recht und Völkerrecht, Heidelber, v. 74, n. 2, p. 367-391, 2014.

2 DUMONT, Gérard-François. L'Ukraine, une terre étrangère pour la Russie? Géostratégiques, Paris, n. 43, p. 69-90, nov. 2014.

3 MCGEE, Robert. Should crimea secede from Ukraine and become part of Russia (Again)? Journal of Accounting, Ethics and Public Policy, v. 2, n. 2, p. 1- 7, March 2, 2014.

4 ENGLE, Eric. A New Cold War? Cold Peace. Russia, Ukraine, and NATO. The University of St. Thomas Law Journal, Houston, n. 59, p. $97-174,2015$.

5 Nesse sentido, coloca Christakis: “Or, c'est précisément l'illicéité de l'intervention militaire russe en Crimée qui rend le processus de sécession et son annexion illicites. La conséquence qui en résulte est une obligation de non-reconnaissance de la nouvelle situation". Tradução livre autora: "Mas é precisamente a ilegalidade da intervenção militar russa na Crimeia que torna o processo de secessão e sua anexação ilegal. A conseqüência é uma obrigação de não reconhecimento da nova situação." CHRISTAKIS, Theodore. Les Conflits de Sécession en Crimée et dans l'Est de l'Ukraine et Le Droit International. Journal du Droit International, p. 23-48, 2014.
No meio desse conflito, o Voo comercial da Malaysia Airlines MH17 é abatido no leste da Ucrânia, em uma zona controlada pelos separatistas pró-Rússia. Todas as 298 pessoas a bordo, das mais diversas nacionalidades, morreram.

Muito embora as investigações oficiais, realizadas sob o manto da Resolução n. ${ }^{\circ} 2166$ do Conselho de Segurança da ONU, sequer tenham sido finalizadas, familiares de vítimas da queda do voo, invocando violações a direitos humanos, acionaram a Ucrânia perante a Corte Europeia de Direitos Humanos.

Mas quais seriam os fundamentos jurídicos e fáticos existentes no caso em apreço, que respaldam e dão sustento à ação dos familiares de vítimas? Preliminarmente, é necessário sopesar a própria legitimidade processual da Ucrânia, no polo passivo, para, num segundo momento, verificar a sua responsabilidade internacional por violação a direitos humanos.

Isso porque os dados oficiais até o momento informam que o abate ocorreu em uma zona controlada por separatistas pró-Rússia. Assim, caso seja comprovado um efetivo controle pelo governo russo desse movimento, com base no teste desenvolvido pela Corte Internacional de Justiça (CIJ) originariamente no Caso Nicarágua v. Estados Unidos da América 1986 ria uma responsabilidade extraterritorial da Rússia pelo ocorrido.

No entanto, além de o teste ser bastante rigoroso, como se verá ao longo desse estudo, seria bastante difícil afastar a obrigação primária da Ucrânia de garantir o gozo e a observância dos direitos humanos em seu território, nomeadamente no seu espaço aéreo, já que, assim, ela se comprometeu internacionalmente por meio da Convenção Europeia de Direitos Humanos.

Destarte, considerando-se a ausência de um due diligence pela Ucrânia, que mesmo depois de ter 4 aviões militares seus abatidos dias antes do Voo MH17, nada fez no sentido de fechar o seu espaço aéreo, como não a considerar parte legitima e cobrar sua responsabilidade, com fundamento na proteção internacional dos direitos humanos?

6 INTERNATIONAL COURT OF JUSTICE. Nicaragua vs. United States of America. Sentence on June 27, 1986. Available at: $<$ http: $/ /$ www.icj-cij.org/docket $/$ ?sum $=367 \& p 1=3 \& p 2=3 \&$ case $=7$ 0\&p3=5>. Access on: 16 dec. 2015. 
Destaca-se que essa proteção nasce para superar o próprio problema gerado pela positivação nacionalista, que deu respaldo às terríveis atrocidades cometidas no século XX, bem como para evitar que a interpretação unilateral dos direitos humanos pelos Estados seja usada como um instrumento para violações disfarçadas.

A proteção internacional é, portanto, subsidiária, a fim de que os Estados, ao falharem em promover os direitos humanos, inclusive no seu dever de prevenção e due diligence, sejam responsabilizados internacionalmente. Ou seja, quando esgotadas as vias internas, a tutela no âmbito internacional emerge com base no caráter objetivo que possuem tais direitos.

Para bem operacionalizar tal proteção internacional, vivenciou-se a criação de mecanismos, tanto de cunho global quanto regional, de natureza judicial ou quase judicial. Alguns desses, e é o que mais se deve dar destaque, possibilitam o acesso direto pelos indivíduos, sem qualquer necessidade de proteção diplomática, de cunho extremamente político, baseada — ademais na nacionalidade.

É com foco nessa valorização dos indivíduos na ordem internacional que houve a possibilidade de os familiares de vítimas do Voo MH17 recorrerem à Corte Europeia de Direitos Humanos, para responsabilizar a Ucrânia. Mas será que estariam, ademais, preenchidos os requisitos necessários para isso? Diante das peculiaridades do caso, quando pode ser considerado que houve um esgotamento das vias internas? E quais seriam essas?

Dessa feita, o estudo apresentado neste artigo, que se apoia no método dedutivo de abordagem de dados, busca apresentar fundamentos, com base na doutrina, em instrumentos normativos e na jurisprudência de Cortes Internacionais, da responsabilidade internacional da Ucrânia pela violação a direitos humanos perpetuada no seu espaço aéreo, afastando, pois, a responsabilidade extraterritorial da Rússia. Pretende-se, ademais, verificar como a Corte Europeia de Direitos Humanos pode ser considerada o fórum mais conveniente para apreciação do caso envolvendo o Voo MH17, apontando quais seriam os requisitos necessários para tanto. Em termos de utilidade e contribuição prática, a proposta deste trabalho consiste em, em última análise, fazer uma exposição indutiva da proteção internacional dos direitos humanos, partindo de um caso concreto; e uma releitura da responsabilidade estatal por omissão, confrontando, para tanto, diferentes decisões das cortes internacionais, mais especificamente as da Corte Internacional de Justiça, da Corte Europeia de Direitos Humanos e do Tribunal Penal para a ex-Iugoslávia.

\section{Teste do EFETIVo CONTROle: AFASTANDO A RESPONSABILIDADE EXTRATERRITORIAL DA RÚSSIA}

Em 9 de setembro de 2014, foi apresentado o relatório preliminar da investigação ${ }^{7}$ sobre a queda do avião na Ucrânia. Este concluiu que o Voo MH17 da Malaysia Airlines explodiu no ar provavelmente como resultado de um dano estrutural causado por um grande número de objetos de alta-tensão que penetraram, a partir do ambiente externo, o avião. Não há indícios de que a queda do avião teria sido causada por uma falha técnica ou por ações da tripulação.

Segundo Bachmann ${ }^{8}$, pode-se, nesse caso, estar diante de crime de guerra, genocídio ou até terrorismo. Com relação a essa última possibilidade, o caso do Voo MH17 traz alguma semelhança com o Caso Lockerbie, já que esse também versou sobre a explosão de avião civil, que, segundo investigações dos Estados Unidos e da Escócia, decorreu de ato terrorista?

7 KINGDOM OF NETHERLANDS. Dutch Safety board releases preliminary report on flight $M H 17$. Available at: <http://www.thenetherlands.org/news/2014/09/mh17-preliminary-report.html > . Access on: 30 jul. 2015.

8 BACHMANN, Sascha-Dominik Oliver Vladimir. Malaysia airlines flight MH17: the day Russia became a state sponsor of terrorism. Amicus Curiae, London, n. 95, p. 1-3, Aug. 2013.

9 Em 21 de dezembro de 1988, uma bomba no Voo 103 da Pan Am, que sobrevoava a cidade de Lockerbie na Escócia, explodiu, matando 259 passageiros e tribulantes, bem como 11 residentes da cidade de Lockerbie. Tanto o Lord Advocate of Scotland e o Grand Jury of US acusaram dois cidadãos líbios como responsáveis pela explosão. Consequentemente, tanto o Reino Unido, quanto os Estados Unidos, requisitaram à Líbia a extradição dos nacionais, para que a prossecução criminal ocorresse alternativamente em algum desses Estados. Alegando que em conformidade com a Convenção de Montreal as autoridades libanesas teriam jurisdição sobre o caso, a Líbia acionou a Corte Internacional de Justiça em 1971 (INTERNATIONAL COURT OF JUSTICE. Libya vs. United States of America. Sentence on Sept 23, 1971. Available at: $<$ http:/ $/$ www.icj-cij.org/docket/index.php?sum $=460 \&$ code $=$ lus\& $\mathrm{p} 1=3 \& \mathrm{p} 2=3 \&$ case $=89 \& \mathrm{k}=82 \& \mathrm{p} 3=5>$. Access on: $16 \mathrm{dec}$. 2015; e INTERNATIONAL COURT OF JUSTICE. United Kingdom of Great Britain and Northern Ireland v. Albania. 1948. Sentence on Mars 25, 1948. Available at: <http://www.icj-cij.org/docket/index. php?p1 $=3 \& p 2=3 \&$ case $=1 \& p 3=4>$. Access on: 16 dec. 2015). Em 2003, as partes notificaram a CIJ da celebração de acordo, no sentido de extinguir o processo. Os acusados foram julgados, pois, em um 
Apesar, então, de não se ter nenhuma conclusão (até o momento) acerca da autoria dos fatos ${ }^{10}$, muitas acusações preliminares foram tecidas aos insurgentes pró-Rússia, grande parte fundadas na própria declaração dada por esses ${ }^{11,}$ de que teriam abatido o Voo MH17 por engano. Será que nessa hipótese pode-se falar em responsabilidade da Rússia, pelo controle exercido sobre esses insurgentes? Está-se diante de uma responsabilidade extraterritorial?

A jurisprudência internacional vem sustentando há tempos que, para configurar a responsabilidade extraterritorial, se faz necessário o efetivo controle por parte do terceiro Estado, que no caso seria a Rússia. Nesse sentido, não se pode deixar de citar o caso Nicarágua v. Estados Unidos da América, julgado pela Corte Internacional de Justiça (CIJ) em $1986^{12}$.

O caso versa sobre a queda do regime ditatorial na Nicarágua, por meio de movimento popular, que levou ao poder a oposição socialista, do movimento sandinista. Em contraposição a esses, havia o CONTRAS (denominação dada ao grupo contrarrevolucionário da Nicarágua), integrado, inclusive, por facções leais à ex-ditadura. Esses eram financiados pelo governo dos Estados Unidos, primeiramente com financiamento direto e, quando esse foi proibido pelo Congresso da Nicarágua, indireto, por meio da venda de armas.

Por tal financiamento, Nicarágua submeteu o caso à Corte Internacional de Justiça em face dos Estados Unidos da América, alegando que esse país teria violado a sua soberania. Ademais, ao encorajar o CONTRAS (denominação dada ao grupo contrarrevolucionário da Nicarágua) a praticar violações aos direitos humanos (tais como, assassinatos e sequestros de cidadãos da Ni-

tribunal neutro na Holanda, composto por cinco juízes escoceses. 10 A previsão de divulgação oficial das investigações está prevista para outubro de 2015 DUTCH SAFETY BOARD. Investigation Crash MH17. July, 2014. Available at: < http://www.onderzoeksraad. $\mathrm{nl} /$ en/onderzoek/2049/investigation-crash-mh17-17-july-2014/ inzage/1643/progress-of-the-mh17-investigation\#fasen>. Access on: 16 dec. 2015.

11 HALL, John. We shot down MH17 thinking it was Ukrainian cargo plane'. MailOnline, London, July 24, 2014. Available at: <http://www.dailymail.co.uk/news/article-2703873/We-shotMH17-thinking-Ukrainian-cargo-plane-Sensational-admission-proRussian-says-realised-mistake-came-bodies-children-not-militarycrew.html>. Access on: 16 dec. 2015.

12 INTERNATIONAL COURT OF JUSTICE. Nicaragua vs. United States of America. Sentence on June 27, 1986. Available at: $<$ http: $/ /$ www.icj-cij.org $/$ docket $/$ ?sum $=367 \& p 1=3 \& p 2=3 \&$ case $=7$ $0 \& p 3=5>$. Access on: 16 dec. 2015. carágua), deveria ser condenado e responsabilizado por tais atos.

Essa última alegação é a mais pertinente à investigação da teoria do efetivo controle. E sobre esta, analisando o caso, a CIJ distinguiu em duas classes os grupos como o CONTRAS (denominação dada ao grupo contrarrevolucionário da Nicarágua), que não são juridicamente vinculadas a um Estado, mas podem atuar em nome destes. Assim, têm-se aqueles que são totalmente dependentes do Estado estrangeiro, inclusive com planejamento e direção; e outros que, embora financiados, mantêm certo grau de independência do Estado financiador.

Com base em tal distinção, a CIJ entendeu que o CONTRAS caracterizava-se como esse segundo grupo. Assim, não houve o efetivo controle de suas ações pelos Estados Unidos, uma vez que inexistiu a emissão de instruções em relação a operações específicas, nem o controle da execução dessas, com a pressão necessária para que fossem realizadas, razão pela qual a CIJ afastou a responsabilização do Estado americano. Essa análise ficou conhecida como teste do efetivo controle.

Esse teste foi posteriormente revisto pelo Tribunal Penal Internacional para a ex-Iugoslávia no caso Tadić $^{13}$, de uma maneira mais ampla do que o aplicado no caso acima mencionado. No entanto, Cassese ${ }^{14}$ destaca que o teste foi utilizado para justificar a competência do Tribunal e a configuração dos crimes como internacionais, razão pela qual essa amplitude deve ser interpretada com ressalva, ainda mais porque o caso não versou sobre responsabilidade Estatal.

Mais recentemente, cita-se a utilização do teste pela CIJ quando do julgamento do genocídio ocorrido em Srebrenica pelas forças armadas do Exército servo-bósnio em 1995, atribuído à República Federal da Iugoslávia ${ }^{15}$. Nessa oportunidade, a Corte reafirmou o teste nos moldes originais, rechaçando aquele utilizado pelo Tribunal Penal para a ex-

13 UNITED NATIONS. International Tribunal for the Prosecution of Persons Responsible for Serious Violations of International Humanitarian Law Committed in the Territory of the Former Yugoslavia since 199. Prosecutor v. Du[Ko Tadi]. Sentence on July 15, 1999. Available at: <http://www.icty.org/x/cases/tadic/acjug/en/tad-aj990715e. pdf $>$. Access on: 16 dec. 2015.

14 CASSESE, Antonio. The Nicaragua and tadić tests revisited in light of the ICJ judgment on genocide in Bosnia. The European Journal of International Law, Oxford, v. 18 n. 4, p. 649-668, 2007.

15 INTERNATIONAL COURT OF JUSTICE. Case Bosnia and Herzegovina vs. Serbia and Montenegro. Sentence on July 11, 2006. Available at: <http://www.icj-cij.org/docket/files/91/13687.pdf>. Access on: 16 dec. 2015. 
-Iugoslávia. Nesse sentido, Gill ${ }^{16}$ esclarece:

On this point, the Court did not follow the ICTY's standard of overall control in relation to Yugoslavia/Serbia's relationship to the Bosnian Serb armed forces and militias, instead it reiterated its own standard of effective control which it had first put forward in its 1986 Nicaragua decision. Yugoslavia's responsibility was limited to its failure to (attempt to) prevent the massacre and did not encompass direct responsibility for either the commission of genocide or complicity in the commission of genocide ${ }^{17}$.

Assim, para que a Rússia possa ser considerada responsável no caso em apreço, há a necessidade de comprovação de que, além do abate do Voo ter sido provocado pelo movimento pró-Rússia, esses agiram sob o efetivo controle ${ }^{18}$ da Rússia, considerado de maneira mais estrita do que no caso Tadić.

Destarte, sem um relatório final das investigações, não há como sustentar a priori tal responsabilidade. No mesmo sentido recentes posicionamentos da Corte Europeia de Direitos Humanos que afastam o teste do efetivo controle.

Nesse sentindo, a Corte tem entendido como responsável o Estado onde foram perpetuadas as violações aos direitos humanos, independentemente de ter ocorrido controle ou apoio de outro Estado na prática do ato. Esse é o precedente estampado no caso Ilascu v. Moldova e Rússia julgado em $2004^{19}$. O caso é decorrente da Guerra da Transnístria, em que por meio de um sentimento separatista, apoiado pela Rússia, essa região desejava ser independente e se separar da Moldá-

16 GILL, T. D. The genocide case: reflections on the ICJ's decision in Bosnia-Herzegovina v Serbia. Available at: <http://www.haguejusticeportal.net/index.php?id=7266> . Access on: 16 july 2015 .

17 Tradução livre autora: Nesse ponto, a Corte não seguiu o teste do Tribunal Penal para a ex-Iugoslávia de controle total em relação ao relacionamento entre Iugoslávia/Sérvia para as forças armadas servo-bósnias e milícias; em vez disso, reiterou o seu próprio padrão de controle efetivo apresentado pela primeira vez na sua decisão sobre Nicarágua em 1986. A responsabilidade da Iugoslávia foi limitada à sua incapacidade de (tentar) evitar o massacre e não abrange a responsabilidade direta com a realização do genocídio ou com a sua cumplicidade em relação a essa realização. GILL, T. D. The Genocide case: reflections on the ICJ's decision in Bosnia-Herzegovina v Serbia. Available at: <http://www.haguejusticeportal.net/index. php?id=7266> . Access on: 16 july 2015 .

18 Destaca-se que o efetivo controle também está previsto no Projeto da Comissão de Direito Internacional das Nações Unidas sobre Responsabilidade Internacional dos Estados de 2001.

19 EUROPEAN COURT OF HUMAN RIGHTS. Ilascu v. Moldova and Russia. Sentence on July 08, 2004. Available at: <http:// hudoc.echr.coe.int/eng?i=001-59454>. Access on: 16 dec. 2015. via. A corte, assim, estabeleceu:

quando um Estado contratante éimpedido de exercer a sua autoridade sobre a totalidade do seu território por uma situação de fato constrangedora, como quando um regime separatista está configurado, seja ou acompanhado por uma ocupação militar do outro Estado, não por isso deixa de ter jurisdição na acepção do artigo $1^{\circ}$ da Convenção sobre a parte do seu território temporariamente sujeita a uma autoridade local sustentada por forças rebeldes ou por outro Estado. [...]. O Estado em questão deve esforçar-se, com todos os meios legais e diplomáticos à sua disposição vis-à-vis Estados estrangeiros e organizações internacionais, para continuar a garantir o gozo dos direitos e liberdades definidos na Convenção ${ }^{20 .}$

No entanto, entende-se não ser cabível aplicar nesse contexto o recente precedente do caso Cyprus v Turkey $^{21}$, uma vez que nesse houve efetiva invasão militar por parte da Turquia em Cyprus. Dessa feita, veja-se como a Ucrânia poderia ter impedido as violações que ocorreram no espaço aéreo sobre sua soberania, o que faz emergir a sua responsabilidade.

\section{RESPONSABILIDAdE da UCRÂNIA PELO NÃO FECHAMENTO DO SEU ESPAÇO AÉREO}

Muito pouco antes da queda do Voo MH17, 4 aviões militares ucranianos já tinham sido abatidos desde de junho de 2014 pelos insurgentes ${ }^{22}$. Dois desses foram abatidos em alta altitude, caso similar ao que ocorreu com o Voo MH17.

Será que, diante desse cenário, não seria previsível o evento danoso? E caso fosse, teria a Ucrânia, por meio de obrigações assumidas no plano internacional, obrigação de evitar tal dano, empreendendo esforços para que esse não ocorresse? Há responsabilidade internacional? Qual é a responsabilidade primária?

Acredita-se que sim, já que houve descumprimento de dever previamente assumido. Veja-se, a Ucrânia, por ser membro do Conselho Europeu, participa do sistema

20 Tradução livre autora.

21 EUROPEAN COURT OF HUMAN RIGHTS. Cyprus v. Turkey, 2014. Sentence on May 10, 2001. Available at: < http://hudoc. echr.coe.int/eng?i=001-59454>. Access on: 16 dec. 2015.

22 WHY WAS MH17, a Civilian Airliner, Flying over a War Zone? The Economist, London, July 21, 2014. Available at: < http://www. economist.com/blogs/economist-explains/2014/07/economistexplains-14>. Access on: 16 dec. 2015. 
europeu de proteção aos direitos humanos e está vinculada à Convenção Europeia de Direitos Humanos.

E quais os deveres previstos na Convenção que foram violados? $\mathrm{O}$ direito à vida, previsto no artigo $2^{\circ}$, e o direito ao respeito pela vida privada e familiar, previsto no artigo $8^{\circ}$. Mas será que esses deveres existem também no que toca à prevenção e independem de culpa ou dolo? Trata-se de uma responsabilidade objetiva?

Nessa perspectiva, este artigo assenta-se nas lições de Cançado Trindade ${ }^{23}$, referentes ao fato de que a responsabilidade no que toca aos direitos humanos é objetiva ou absoluta, calcada no elemento do risco, não sendo necessário identificar erro ou dolo. Conclui Cançado Trindade ${ }^{24}$ :

no meu entendimento, a responsabilidade internacional do estado está configurada desde o momento que esse falha em cumprir com uma obrigação internacional, independente da verificação do erro ou da culpa de sua parte, e a ocorrência de um dano adicional. No lugar de uma atitude psicológica presumida ou erro por parte dos agentes públicos, o que realmente determina é a conduta objetiva do Estado ( a due diligence para evitar às violações aos direitos humanos). Pode-se, assim, chegar no estabelecimento de uma objetiva ou absoluta responsabilidade do Estado a partir da violação de suas obrigações internacionais convencionais de proteção dos direitos humanos. Nessa responsabilidade objetiva reside o dever de prevenção ${ }^{25}$.

Destarte, a Ucrânia tinha sim o dever de prevenir o ocorrido, não empreendendo a due diligence que lhe era exigida. Reforça esse posicionamento o próprio Projeto da Comissão de Direito Internacional das Nações Unidas sobre Responsabilidade Internacional dos Estados de $2001^{26}$, ao prever a responsabilidade Estatal por atos omissivos.

Nesse mesmo projeto, há previsão de exclusão de responsabilidade por força maior, no artigo $23^{27}$, no se-

23 TRINDADE, Antônio Cançado. The construction of a bumanized international law. Leiden: Brill, 2014.

24 TRINDADE, Antônio Cançado. The construction of a bumanized international law. Leiden: Brill, 2014. p. 254.

25 Tradução livre autora.

26 UNITED NATIONS. Draft Articles on Responsibility of States for Internationally Wrongful Acts, with Commentaries. Available at: $<$ http://legal.un.org/ilc/texts/instruments/english/commentaries/9_6_2001.pdf>. Access on: 16 dec. 2015.

27 UNITED NATIONS. Draft Articles on Responsibility of States for Internationally Wrongful Acts, with Commentaries. Available at: $<$ http://legal.un.org/ilc/texts/instruments/english/commentaries/9_6_2001.pdf>. Access on: 16 dec. 2015. guinte sentindo:

the wrongfulness of an act of a State not in conformity with an international obligation of that State is precluded if the act is due to force majeure, that is the occurrence of an irresistible force or of an unforeseen event, beyond the control of the State, making it materially impossible in the circumstances to perform the obligation ${ }^{28}$.

Acredita-se que, pelo nível de agravamento que os conflitos encontravam-se no território ucraniano, não se pode dizer que o abate do Voo foi totalmente imprevisto. Há relatos que a Eurocontrol, organização que gerencia o espaço aéreo europeu, teria instado, muito embora sem força vinculativa, o governo ucraniano para que este fechasse o seu espaço aéreo, após as reiteradas quedas de aviões militares ucranianos por parte dos rebeldes pró-Rússia ${ }^{29}$.

Diante de todo cenário, outra conclusão não há de que a Ucrânia efetivamente assumiu o risco de que violações como as perpetuadas com o abate do Voo MH17 ocorressem. Especula-se que houve interesse financeiro por parte da Ucrânia, já que essa recebia taxas pelo trânsito aéreo, cerca de 700 voos por dia, o que equivale, aproximadamente, a muitos milhões por mês ${ }^{30}$.

Com base no que foi anteriormente exposto nesse estudo, não há como, pois, afastar a responsabilidade da Ucrânia. Além disso, não podemos deixar de mencionar um importante precedente da Corte Internacional de Justiça no Caso do Canal de Corfu, que versa igualmente sobre atos omissivos para parte da Albânia ${ }^{31}$, uma vez que dois destroyers britânicos explodiram por causa de minas nas águas territoriais da Albânia, em 1945, o que

28 Tradução livre autora: "A ilicitude de um ato de um Estado que não esteja em conformidade com uma obrigação internacional desse Estado está excluída se o ato é devido a força maior, que é a ocorrência de uma força irresistível ou de um imprevistoevento, fora do controle do Estado, tornando materialmente impossível nas circunstâncias cumprir a obrigação".

29 PANCEVSKI, Bojan. Kiev Was Urged to Close Airspace Days Before MH17 Tragedy. Russia Insider, Greenwich, Dec. 8, 2014. Available at: <http://russia-insider.com/en/ukraine/2014/12/08/0323-34pm/kiev_was_urged_close_airspace_days_mh17_tragedy $>$. Access on: 16 dec. 2015.

30 HUDSON, Alexandra. MH17 Victim's Mum is Suing Ukraine for $\$ 1 \mathrm{~m}$ : for Failing to Close Country's Airspace. Mirror, Liverpool, Nov 30. 2014. Available at: <http://www.mirror.co.uk/news/ world-news/mh17-victims-mum-suing-ukraine-4724052>. Access on: 16 dec. 2015.

31 INTERNATIONAL COURT OF JUSTICE. United Kingdom of Great Britain and Northern Ireland v. Albania. 1948. Sentence on Mars 25, 1948. Available at: <http://www.icj-cij.org/docket/index. php?p1 $=3 \& p 2=3 \&$ case $=1 \& p 3=4>$. Access on: 16 dec. 2015. 
acarretou a morte dos tripulantes, além dos danos materiais.

A CIJ expressou, em tal ocasião, que cada Estado não pode permitir que seu território seja utilizado para a prática de atos contrários aos direitos dos outros estados. Assim, mesmo que os responsáveis pelas minas não tenham sido identificados, a Albânia seria, sim, responsável, no seguinte sentido:

\begin{abstract}
as obrigações que incumbiam as autoridades albanesas consistiam em fazer conhecida, no interesse da navegação em geral, a existência de um campo de minas nas águas territoriais albanesas e em advertir os navios de guerra britânicos, no momento de sua aproximação, do perigo iminente ao qual os expunha esse campo de minas. Essas obrigações fundam-se não na Convenção VIII de Haia de 1907, que é aplicável em tempos de guerra, mas sobre certos princípios gerais e bem reconhecidos, tais como as considerações elementares de humanidade, mais absolutas ainda em tempo de paz do que em tempo de guerra; o princípio da liberdade das comunicações marítimas; e a obrigação de todo Estado de não permitir que seu território seja utilizado para o fim de atos contrários aos direitos dos outros Estados ${ }^{32}$.
\end{abstract}

Fundamentadas as razões pelas quais a Ucrânia pode ser responsabilizada pelo dever de ter prevenido o ocorrido, vejamos qual seria o fórum mais adequado para tanto.

\section{Forum Conveniens: Corte Europeia de Direitos Humanos}

Em face dessa possível responsabilidade da Ucrânia, ao falhar em prevenir violações aos direitos humanos, qual seria o fórum mais conveniente para julgá-la? Está-se diante de um Grotian Moment, para criação de um novo foro?

Uma proposta de criação de um Tribunal Internacional Criminal para o Voo MH17 da Malaysia Airlines foi apresentada em julho 2015 ao Conselho de Segurança das Nações Unidas. No entanto, não foi possível a adoção desta, já que houve o veto da Rússia ${ }^{33 .}$

32 INTERNATIONAL COURT OF JUSTICE. United Kingdom of Great Britain and Northern Ireland v. Albania. 1948. Sentence on Mars 25, 1948. Available at: <http://www.icj-cij.org/docket/index. php?p1 $=3 \& p 2=3 \&$ case $=1 \& p 3=4>$. Access on: 16 dec. 2015.

33 UNITED NATIONS. Security Council fails to adopt proposal to create tribunal on crash of Malaysian Airlines flight MH17. Available at: $<$ http://www.un.org/apps/news/story.asp?NewsID=51530>. Access on: 16 dec. 2015
O veto foi recebido com desapontamento, especialmente por parte da Malásia. A proposta de tribunal, que seria aprovada por meio de resolução, possibilitaria uma investigação e um posterior julgamento criminal do caso $^{34}$.

Mas, então, tendo com base as cortes internacionais já existentes, quais poderiam ser instadas a se manifestar sobre o caso? Primeiramente, fala-se na CIJ, que é a mais alta corte no sistema das Nações Unidas.

Esta, no entanto, não está aberta a petições de vítimas, nem sequer tem a capacidade de promover persecuções criminais individuais. Possui, por outro lado, atribuição para determinar quando Estados são responsáveis por certos atos, como pelo financiamento de grupos armados (Rússia) ${ }^{35}$ ou pela falha de não fechar o seu espaço aéreo (Ucrânia).

Ocorre que essa submissão à jurisdição da CIJ não é compulsória, deve haver um reconhecimento da sua competência contenciosa. André de Carvalho Ramos ${ }^{36}$ menciona que esse reconhecimento pode ocorrer de quatro formas: (a) cláusula Raul Fernandes, (cláusula facultativa de jurisdição obrigatória), (b) previsão em acordos específicos, (c) reconhecimento para o caso, e (d) prorrogação da competência.

Nesse sentido, destaca-se que nem a Rússia nem a Ucrânia aderiram à cláusula Raul Fernandes. E, da mesma forma, supõe-se que seja bastante improvável que essas venham a reconhecer caso eventualmente acionadas para o deslinde do caso em apreço.

Outra corte que pode assumir um papel interessante é o Tribunal Penal Internacional, responsável por julgar certos crimes internacionais, nomeadamente aqueles considerados como contra a humanidade. Nesse sentido, é essencial definir e caracterizar os atos que ocasionaram o abate dos $\mathrm{MH} 17$, até mesmo porque esse tribunal não possui competência no que toca a atos de terrorismo ${ }^{37}$.

34 UNITED NATIONS. Security Council fails to adopt proposal to create tribunal on crash of Malaysian Airlines flight MH17. Available at: $<$ http://www.un.org/apps/news/story.asp?NewsID=51530>. Access on: 16 dec. 2015.

35 AUSTRALIAN NATIONAL UNIVERSITY. MH17: the legal path to justice. Available at: <https://law.anu.edu.au/news/law/ mh17-legal-path-justice>. Access on: 2 aug. 2015.

36 RAMOS, André de Carvalho. Processo internacional de direitos bumanos. São Paulo: Saraiva, 2014.

37 AUSTRALIAN NATIONAL UNIVERSITY. MH17: the legal path to justice. Available at: <https://law.anu.edu.au/news/law/ 
No entanto, cabe ressaltar que nem a Rússia nem a Ucrânia são partes do Estatuto de Roma. Esses dois Estados o assinaram, mas não ratificaram. Ainda que seja possível o reconhecimento da jurisdição por não membros, conforme o artigo 12 do Estatuto de Roma, nada garante que esse reconhecimento seja de fato exercido ${ }^{38}$.

Ao lado dessas Cortes, há aquelas decorrentes dos sistemas regionais de proteção aos direitos humanos, tais como a Corte Europeia de Direitos Humanos. O grande destaque que deve ser dado é que essa, diferentemente das apontadas acima, permite o acesso direto por individuais.

Segundo André de Carvalho Ramos ${ }^{39}$, a apresentação de petições individuais teve início com o Protocolo 11. Em 2010, a Corte Europeia totalizou um número de recebimento de mais de 61 mil petições ${ }^{40}$, o que é deveras expressivo.

Esse modelo de petições constitui uma valorização do indivíduo na ordem internacional fantástico, que deve ser bem elogiado. É adotado, ademais, nos mecanismos quase judiciais, tais como os comitês de tratados específicos.

Um destaque importante refere-se ao fato de que a Corte Europeia não exige que o autor tenha nacionalidade do Estado réu ou a estadia regular neste. Essa possibilidade é muito importante, especialmente no caso em apreço, já que nenhuma das vítimas do Voo MH17 eram ucranianas.

André de Carvalho Ramos ${ }^{41}$ enumera fatores que podem gerar a inadmissibilidade da petição:

os motivos da inadmissibilidade são os seguintes:
1) ausência de esgotamento dos recursos internos;
2) perda do prazo de seis meses a contar da data
da decisão interna definitiva para peticionar à Corte
EDH; 3) anonimato da petição; 4) coisa julgada,
caso a petição seja essencial, idêntica a uma petição
anteriormente examinada pela Corte ou já submetida

mh17-legal-path-justice>. Access on: 2 aug. 2015.

38 DOBRIANSKY, Paula J. Russia should be prosecuted for its crimes against humanity. The Washington Post, Washington, Feb. 12, 2015. Available at: <https://www.washingtonpost.com/ opinions/the-icc-must-prosecute-russia/2015/02/12/1755105cb2c0-11e4-827f-93f454140e2b_story.html>. Access on: $16 \mathrm{dec}$. 2015.

39 RAMOS, André de Carvalho. Processo internacional de direitos bumanos. São Paulo: Saraiva, 2014.

40 RAMOS, André de Carvalho. Processo internacional de direitos humanos. São Paulo: Saraiva, 2014.

41 RAMOS, André de Carvalho. Processo internacional de direitos bumanos. São Paulo: Saraiva, 2014. a outra instância internacional de direitos humanos sem qualquer fato novo; 5) teor incompatível com o disposto na Convenção ou manifestamente mal fundada ou com caráter abusivo; e, finalmente, 6) não ocorrência de qualquer prejuízo significativo ou matéria de grave indagação, salvo se o respeito pelos direitos exigir uma apreciação da petição.

Assim, faz-se necessário, dentre os requisitos, o prévio esgotamento dos recursos internos, para que a Corte Europeia de Direitos Humanos possa ser acionada. Mas, no caso do Voo MH17, quais seriam esses recursos internos? Seriam os da Ucrânia ou os do país de residência das vítimas e/ou seus familiares?

Como o "crime" ocorreu no seu espaço aéreo, evidente que a Ucrânia, de qualquer forma, teria jurisdição para a persecução. Mas diante de toda a fragilidade institucional com as disputas que vêm ocorrendo no local, será que é possível imaginar que essa persecução efetivamente ocorra?

Ademais, considerando as dimensões internacionais, pode-se visualizar a competência de Estados como Holanda, Malásia, Austrália e outros para julgar o caso, com base na jurisdição universal, respaldada na Convenção de Montreal sobre atos ilícitos contra a aviação civil ${ }^{42}$.

Veja-se que dessa forma é muito complicado prever qual seria o esgotamento prévio que os familiares das vítimas deveriam recorrer antes de chegarem até a Corte Europeia de Direitos Humanos. Por outro lado, a própria situação delicada e os inúmeros elementos internacionais do caso não podem servir como entraves à reparação desses familiares. Dessa feita, o caso já instaurado perante a Corte Europeia de Direitos Humanos sem dúvida será paradigmático, até mesmo nas questões preliminares que terá que enfrentar.

\section{Considerações finais}

Ainda que a Rússia pudesse vir a ser responsabilizada com base no teste do efetivo controle cunhado pela CIJ no caso Nicarágua v. Estados Unidos da América $(1986)^{43}$ e revisto, mais recentemente, no caso Bósnia

42 AUSTRALIAN NATIONAL UNIVERSITY. MH17: the legal path to justice. Available at: <https://law.anu.edu.au/news/law/ mh17-legal-path-justice>. Access on: 2 aug. 2015.

43 INTERNATIONAL COURT OF JUSTICE. Nicaragua vs. United States of America. Sentence on June 27, 1986. Available at: $<$ http: $/ /$ www.icj-cij.org $/$ docket $/$ ?sum $=367 \& \mathrm{p} 1=3 \& \mathrm{p} 2=3 \&$ case $=7$ 
e Herzegovina v. Sérvia e Montenegro (2006) ${ }^{44}$, não há como afastar a responsabilidade primária da Ucrânia por violações aos direitos humanos ocorridos no seu espaço aéreo, muito embora essas tenham sido provocadas por insurgentes. Nesse sentido, exalta-se o entendimento da Corte Europeia de Direitos Humanos (Ilascu v. Moldávia e Rússia, 2004) ${ }^{45}$ de que determinado Estado, mesmo que possua em seu território um regime separatista configurado, deve esforçar-se, por todos os meios legais e diplomáticos disponíveis, para continuar a garantir os direitos previstos na Convenção Europeia de Direitos Humanos.

Assim, houve falha da Ucrânia no seu dever de proteção e due diligence, fazendo emergir a sua responsabilidade. Essa independe de culpa ou dolo por parte do Estado violador, sendo, pois, objetiva e, até mesmo, absoluta.

O não fechamento do espaço aéreo da Ucrânia, mesmo após ter vários aviões seus abatidos, constitui uma grave omissão. A responsabilidade internacional por atos omissivos já foi apreciada no caso Reino Unido da Grã Bretanha e Irlanda do Norte v. Albânia julgado pela CIJ, cuja conclusão aplica-se analogicamente ao caso do Voo MH17: "é obrigação de todo Estado de não permitir que seu território seja utilizado para o fim de atos contrários aos direitos dos outros Estados" ${ }^{\prime 4}$.

Em última análise, havendo fundamentos para sustentar a responsabilidade internacional da Ucrânia por violações a direitos humanos, verificou-se, ao longo desse estudo, que a Corte Europeia de Direitos Humanos é o fórum mais conveniente para que essa seja apurada, especialmente considerando-se o acesso a esta por meio dos indivíduos prejudicados pela falha da Ucrânia no seu dever de prevenir. Questão controversa, no entanto, que dependerá de um juízo da Corte, diz respeito ao esgotamento dos recursos internos. Espera-se, todavia, que esse não seja utilizado como entrave à reparação

0\&p3=5>. Access on: 16 dec. 2015.

44 INTERNATIONAL COURT OF JUSTICE. Case Bosnia and Herzegovina vs. Serbia and Montenegro. Sentence on July 11, 2006. Available at: <http://www.icj-cij.org/docket/files/91/13687.pdf>. Access on: 16 dec. 2015

45 EUROPEAN COURT OF HUMAN RIGHTS. Ilascu v. Moldova and Russia. Sentence on July 08, 2004. Available at: <http:// hudoc.echr.coe.int/eng?i=001-59454>. Access on: 16 dec. 2015. 46 INTERNATIONAL COURT OF JUSTICE. United Kingdom of Great Britain and Northern Ireland v. Albania. 1948. Sentence on Mars 25, 1948. Available at: <http://www.icj-cij.org/docket/index. php?p1 $=3 \& p 2=3 \&$ case $=1 \& p 3=4>$. Access on: 16 dec. 2015. dos danos sofridos com o abate, especialmente considerando as grandes peculiaridades do caso.

\section{ReferênCias}

AUSTRALIAN NATIONAL UNIVERSITY. MH17: the legal path to justice. Available at: <https://law.anu. edu.au/news/law/mh17-legal-path-justice $>$. Access on: 2 aug. 2015.

BACHMANN, Sascha-Dominik Oliver Vladimir. Malaysia airlines flight MH17: the day Russia became a state sponsor of terrorism. Amicus Curiae, London, n. 95, p. 1-3, Aug. 2013.

CASSESE, Antonio. The Nicaragua and tadić tests revisited in light of the ICJ judgment on genocide in Bosnia. The European Journal of International Law, Oxford, v. 18 n. 4, p. 649-668, 2007.

CHRISTAKIS, Theodore. Les Conflits de Sécession en Crimée et dans l'Est de l'Ukraine et Le Droit International. Journal du Droit International, p. 23-48, 2014.

DOBRIANSKY, Paula J. Russia should be prosecuted for its crimes against humanity. The Washington Post, Washington, Feb. 12, 2015. Available at: < https://www. washingtonpost.com/opinions/the-icc-must-prosecute-russia/2015/02/12/1755105c-b2c0-11e4-827f93f454140e2b_story.html>. Access on: 16 dec. 2015.

DUMONT, Gérard-François. L'Ukraine, une terre étrangère pour la Russie? Géostratégiques, Paris, n. 43, p. 69-90, nov. 2014.

DUTCH SAFETY BOARD. Investigation Crash MH17. July, 2014. Available at: <http://www.onderzoeksraad.nl/en/onderzoek/2049/investigation-crashmh17-17-july-2014/inzage/1643/progress-of-themh17-investigation\#fasen>. Access on: 16 dec. 2015.

ENGLE, Eric. A New Cold War? Cold Peace. Russia, Ukraine, and NATO. The University of St. Thomas Law Journal, Houston, n. 59, p. 97-174, 2015.

EUROPEAN COURT OF HUMAN RIGHTS. Cyprus v. Turkey, 2014. Sentence on May 10, 2001. Available at: <http://hudoc.echr.coe.int/eng?i=001-59454>. Access on: 16 dec. 2015.

EUROPEAN COURT OF HUMAN RIGHTS. Ilascu v. Moldova and Russia. Sentence on July 08, 2004. Availa- 
ble at: <http://hudoc.echr.coe.int/eng?i=001-59454>. Access on: 16 dec. 2015.

GILL, T. D. The Genocide case: reflections on the ICJ's decision in Bosnia-Herzegovina v Serbia. Available at: <http://www.haguejusticeportal.net/index. php?id $=7266>$. Access on: 16 july 2015.

HALL, John. We shot down MH17 thinking it was Ukrainian cargo plane'. MailOnline, London, July 24, 2014. Available at: < http:/ /www.dailymail.co.uk/news/ article-2703873/We-shot-MH17-thinking-Ukrainiancargo-plane-Sensational-admission-pro-Russian-saysrealised-mistake-came-bodies-children-not-militarycrew.html>. Access on: 16 dec. 2015.

HUDSON, Alexandra. MH17 Victim's Mum is Suing Ukraine for $\$ 1 \mathrm{~m}$ : for Failing to Close Country's Airspace. Mirror, Liverpool, Nov 30. 2014. Available at: <http://www.mirror.co.uk/news/world-news/mh17victims-mum-suing-ukraine-4724052>. Access on: 16 dec. 2015.

INTERNATIONAL COURT OF JUSTICE. Líbya vs. United States of America. Sentence on Sept 23, 1971. Available at: <http://www.icj-cij.org/docket/index.ph $\mathrm{p}$ ? sum $=460 \&$ code $=$ lus \&p $1=3 \& \mathrm{p} 2=3 \&$ case $=89 \& \mathrm{k}=82$ \&p3=5>. Access on: 16 dec. 2015.

INTERNATIONAL COURT OF JUSTICE. United Kingdom of Great Britain and Northern Ireland v. Albania. 1948. Sentence on Mars 25, 1948. Available at: <http://www.icj-cij.org/docket/index. php?p1 $=3 \& \mathrm{p} 2=3 \&$ case $=1 \& \mathrm{p} 3=4>$. Access on: $16 \mathrm{dec}$. 2015.

INTERNATIONAL COURT OF JUSTICE. Case Bosnia and Herzegovina vs. Serbia and Montenegro. Sentence on July 11, 2006. Available at: <http://www. icj-cij.org/docket/files/91/13687.pdf>. Access on: 16 dec. 2015.

INTERNATIONAL COURT OF JUSTICE. Líbya vs. United Kingdom. Sentence on Sept 23, 1971. Available at: <http://www.icj-cij.org/docket/index.php?sum $=46$ $0 \& \mathrm{p} 1=3 \& \mathrm{p} 2=3 \& \mathrm{k}=82 \&$ case $=88 \& \mathrm{p} 3=0>$. Access on: 16 dec. 2015.

INTERNATIONAL COURT OF JUSTICE. Nicaragua vs. United States of America. Sentence on June 27, 1986. Available at: <http://www.icj-cij.org/docket/?s $\mathrm{um}=367 \& \mathrm{p} 1=3 \& \mathrm{p} 2=3 \&$ case $=70 \& \mathrm{p} 3=5>$. Access on: 16 dec. 2015.
KINGDOM OF NETHERLANDS. Dutch Safety board releases preliminary report on flight MH17. Available at: <http://www.the-netherlands.org/ news/2014/09/mh17-preliminary-report.html $>$. Access on: 30 july 2015.

MARXSEN, Christin. The crimea crisis: an international law perspective. Zeitschrift ausländisches öffentliches Recht und Völkerrecht, Heidelber, v. 74, n. 2, p. 367-391, 2014.

MCGEE, Robert. Should crimea secede from Ukraine and become part of Russia (Again)? Journal of Accounting, Ethics and Public Policy, v. 2, n. 2, p, 1-7, March 2, 2014.

PANCEVSKI, Bojan. Kiev Was Urged to Close Airspace Days Before MH17 Tragedy. Russia Insider, Greenwich, Dec. 8, 2014. Available at: <http://russiainsider.com/en/ukraine/2014/12/08/03-23-34pm/ kiev_was_urged_close_airspace_days_mh17_tragedy $>$. Access on: 16 dec. 2015.

RAMOS, André de Carvalho. Processo internacional de direitos humanos. São Paulo: Saraiva, 2014.

TRINDADE, Antônio Cançado. The construction of a humanized international law. Leiden: Brill, 2014.

UNITED NATIONS. Draft Articles on Responsibility of States for Internationally Wrongful Acts, with Commentaries. Available at: <http://legal.un.org/ilc/texts/ instruments/english/commentaries/9_6_2001.pdf>. Access on: 16 dec. 2015.

UNITED NATIONS. International Tribunal for the Prosecution of Persons Responsible for Serious Violations of International Humanitarian Law Committed in the Territory of the Former Yugoslavia since 199. Prosecutor v. Du[Ko Tadi]. Sentence on July 15, 1999. Available at: <http://www.icty.org/x/cases/tadic/ acjug/en/tad-aj990715e.pdf>. Access on: 16 dec. 2015.

UNITED NATIONS. Security Council fails to adopt proposal to create tribunal on crash of Malaysian Airlines flight MH17. Available at: < http://www.un.org/ apps/news/story.asp?NewsID $=51530>$. Access on: 16 dec. 2015.

WHY WAS MH17, a Civilian Airliner, Flying over a War Zone? The Economist, London, July 21, 2014 Available at: <http://www.economist.com/blogs/economistexplains/2014/07/economist-explains-14>. Access on: 16 dec. 2015. 
Para publicar na Revista de Direito Internacional, acesse o endereço eletrônico www.rdi.uniceub.br ou www.brazilianjournal.org.

Observe as normas de publicação, para facilitar e agilizar o trabalho de edição. 